\title{
Bariatric Surgery in the Times of Corona
}

\author{
SK Tyagi ${ }^{1} \cdot$ Rishi Singhal ${ }^{2,3}$
}

Published online: 17 April 2020

(C) Springer Science+Business Media, LLC, part of Springer Nature 2020

These are unprecedented times. However, these are also times where the entire world has tried to stand together as one, and we are witnessing examples of extraordinary human achievements. On 23 March, it was reported that it took a mere 67 days from the first reported case to reach the first 100,000 cases, 11 days for the second and just four days for the third 100,000 cases. To cope with this dramatic surge in the number of patients, one of the strategies has been to cancel all nonurgent operations. This idea has been endorsed by most surgical societies and largely been implemented across the globe. Unfortunately, bariatric surgery has been one of the first disciplines to have been affected by this move.

In the past week, I have received numerous calls from patients requesting for their surgery to be conducted as previously scheduled, some even begging for a place on that last theatre list. Most of these patients were aware of the risks of being admitted to a hospital and the chance of contracting COVID-19. In spite of this, their desperation for the surgery is something we can only attempt to understand. In such unprecedented times, we are seeing even non-urgent cancer procedures being cancelled. Cancer patients have had the sympathy of the health care systems and the emotional and psychological support offered by specialist cancer nurses, cancer psychologists and the public at large. There is also the promise of the earliest available date once the pandemic subsides. Consequently, bariatric patients have been left at the bottom of this pile.

All illness brings with it a huge burden of stress, and patients dealing with morbid obesity are already struggling with discrimination on a daily basis. They have finally managed to get onto a theatre list whereby they can get the treatment they

Rishi Singhal

singhal_rishi@hotmail.com

1 Department of Gastroenterology, Kailashi Hospital, Meerut, India

2 Consultant Bariatric \& Upper GI Surgeon, University Hospital Birmingham NHS Foundation Trust, Birmingham, UK

3 Medical Director, Healthier Weight, Birmingham, UK rightly deserve and the promise of a better quality of life. Now, that long awaited surgery has been once again delayed. To make matters worse, most healthcare systems are prioritising care for COVID-19 patients, followed by cancer patients and then patients with acute illness. Once again, bariatric patients are relegated to being the unsung victims of this crisis.

As bariatric professionals, I feel that we need to do much more to support our patients during this time. Mentally, these are testing times for anyone, leave apart somebody who already has a 'weighty' psychological baggage. To add to that, the quarantine rules are likely to make the fittest of us gain weight, so what can happen to our bariatric patients is not hard to imagine. We need to mobilise and sensitise the entire multidisciplinary team so that we can continue to support these patients via telephonic conversations. We need to look at pharmacological weight management options in an attempt to promote weight loss or at least maintain weight stability. We should conduct webinars and online clinics in order to promote a sense of health and well-being in this vulnerable group of individuals along with a promise of timely surgery. We need to think ahead and prepare for how to deal with the backlog of waiting patients while continuing to see new ones. This will come with its own set of challenges that we should begin looking for answers to. A thought worth considering at this time - Can suffering be prioritised?

To conclude, the famous words of Francis Bacon come to mind, which probably mean more now than they ever have'If we begin with certainties, we shall end in doubts; but if we begin with doubts, and are patient in them, we shall end in certainties'.

\section{Compliance with Ethical Standards}

Conflict of Interest The authors report no conflict of interest.

Publisher's Note Springer Nature remains neutral with regard to jurisdictional claims in published maps and institutional affiliations. 